\title{
Maksimum Azaltılmış Göreli Kat Ötelemelerinin Güncel (DBYBHY2007) ve Yeni Yönetmelik Taslağına (TBDY2016) Göre Mukayesesi
}

\author{
Muhammet Musab ERDEM ${ }^{1}$, Murat BİKÇE ${ }^{* 1}$ \\ ${ }^{1} \dot{I}$ skenderun Teknik Üniversitesi, Mühendislik ve Doğa Bilimleri Fakültesi, \\ Inşaat Mühendisliği Bölümü, Hatay
}

Geliş tarihi: 24.05.2016 Kabul tarihi: 31.05 .2017

$\ddot{\mathbf{O z}}$

Maksimum göreli kat ötelemeleri, yapıların yönetmeliklerce güvenlik açısından sınırlandırıldığı temel parametrelerden biridir. Ülkemizde halen yürürlükte bulunan 2007 Deprem Bölgelerinde Yapılacak Binalar Hakkında Yönetmeliğe göre, elde edilen göreli kat ötelemelerinin sınırları ve kriterleri, 2016 Türkiye Bina Deprem Yönetmelik taslağı ile değişmektedir. Bu çalıșmada, her iki yönetmeliğin "Etkin Göreli Kat Öteleme" hesabı ve sınır şartları detaylı olarak karşılaştırılmışıtır. Taslak yönetmelikte izin verilen göreli kat öteleme sınırlarının, dolgu duvar - çerçeve bağlantısının derzsiz olduğu durum için genel olarak illerin büyük çoğunluğunda arttı̆̆ı, derzli tasarımda ise derzsize göre iki kat yükseldiği anlaşılmaktadır.

Anahtar Kelimeler: Göreli kat ötelemesi, TBDY2016, Elastik tasarım spektral ivmesi

\section{Comparison of Reduced Relative Storey Drifts According to Current Earthquake Code (DBYBHY 2007) and New Draft Earthquake Code (TBDY2016)}

\begin{abstract}
Maximum relative floor displacements are one of the basic parameters that are limited by the regulations in terms of safety for the regulations. According to the Regulation on the Turkish Earthquake Code (TEC) 2007 which are currently in force in our country, the limits and criteria of the relative floor drifts obtained vary according to the TEC 2016 in draft. In this study, the "Effective Relative Floor Shift" account and boundary conditions of both directives are compared in detail. It is understood that the permissible floor folding limits allowed in the draft regulation are increased in the majority of the cases in general, in case of the joint of the filler wall-frame joint, and in the case of the jointed design, two times higher than the joint.
\end{abstract}

Keywords: Relative storey drift, TBDY2016, Elastic design spectral acceleration

*Sorumlu yazar (Corresponding author): Murat BİKÇE, muratbikce@yahoo.com 


\section{GíRiş}

Depreme dayanıklı yapı tasarımı, deprem etkisindeki ülkeler için son derece önemlidir. Bu hedef doğrultusunda gerekli hesap ve kisitlamalar deprem yönetmelikleriyle belirlenmektedir. Deprem kuşağında yer alan ülkemizde yayınlanan deprem yönetmelikleri, deprem sonrası edinilen tecrübeler ve bilimsel gelişmeler 1şığında sürekli bir gelişim halindedir. Yürürlükte bulunan 2007 Deprem Bölgelerinde Yapılacak Binalar Hakkında Yönetmeliğinin (DBYBHY2007), 2016 Türkiye Bina Deprem Yönetmeliği (TBDY2016) taslağı ile yapı tasarım kuralları açısından değişime uğradığ1 anlaşılmaktadır. Göreli kat ötelemeleri, yapının deprem sırasında güvenliğinin sağlaması açısından yönetmeliklerce sınırlandırılmaktadır. Yenilenecek olan yönetmelikte göreli kat öteleme hesap ve sınırlarının da değişeceği görülmektedir.

Yapıların deprem güvenliğini sağlamak amacıyla hemen hemen her ülkenin deprem yönetmeliğinde göreli kat ötelemelerine sınırlamalar getirilmiştir [1]. Bazı yönetmeliklerde göreli kat öteleme sinırların belirlenmesinde yapısal olmayan dolgu duvarların deprem sirasında alacağı hasar da göz önünde bulundurulmaktadır [2]. TBDY2016'da [3] de DBYBHY2007'den [4] farklı olarak, dolgu duvar ile çerçeve arasındaki bağlantının bitişik veya derzli olma durumuna göre ayrı ayrı göreli kat öteleme sınırı belirlenmekte ve yapısal olmayan dolgu duvarların hasar almaması yönünde bir düzenleme getirilmektedir [3]. Ayrıca, 2007 yönetmeliğine ilave olarak, zemin türü, inşa edilecek konumun depremselliği, yapının doğal titreşim periyodu, bina önem katsayısı ve dolgu duvar - çerçeve bağlantısı bu hesaba etki eden parametreler olarak ortaya çıkmaktadır. Bundan sonraki tasarımları etkileyecek olan "Etkin Göreli Kat Öteleme" hesabı ve sınırları, her iki yönetmelik şartlarına göre, bu çalışmada detaylı olarak karşılaştırılmıştır. Buna göre, binalarda izin verilen maksimum göreli kat ötelenmeleri her iki deprem yönetmeliğine göre her bir il merkezi için ortaya çıkarılmıştır. Her iki yönetmelikte belirtilen göreli kat ötelemesi kriterlerinin hesap yöntemleri karşılaştırılarak detaylı olarak açıklanmıştır.

\section{GÖRELİ KAT ÖTELEMELERININ SINIRLANDIRILMASI}

\subsection{DBYBHY2007'ye Göre}

DBYBHY2007'de etkin göreli kat ötelemelerinin sınırlandırılma kuralı 2.10.1 bölümünde ifade edilmektedir. Bu kurala göre; yapının her bir deprem doğrultusunda herhangi bir i'inci katta bulunan kolon ve perdeler için hesaplanan etkin göreli kat ötelemelerinin $\left(\delta_{\mathrm{i}}\right)$ en büyük değeri aşağıdaki denklemi sağlaması gerekmektedir.

$$
\frac{\left(\delta_{i}\right)_{\max }}{h_{i}} \leq 0,02
$$

Burada, etkin göreli kat ötelemesi, $\delta_{i}$, kat yüksekliği, $h_{i}$ ile ifade etmektedir. Etkin göreli kat ötelemeleri $\left(\delta_{i}\right)$, taşıyıcı sistem davranış katsayısı, R ile azaltılmış göreli kat ötelemelerinin, $\Delta_{\mathrm{i}}$ çarpımı ile,

$\delta_{i}=R \times \Delta_{i}$

şeklinde elde edilmektedir. Eşitlik 1'deki ifade denklem 2'de yerine konulduğunda azaltılmış göreli kat ötelemelerinin kat içinde müsaade edilen en büyük değeri ortaya çıkmaktadır (Eşitlik 3).

$\left(\Delta_{i}\right)_{\max } \leq \frac{0,02 \times h_{i}}{R}$

\subsection{TBDY2016'ya Göre}

Etkin göreli kat ötelemelerinin sinırlandırılması kural1, DBYBHY2007'de; $h_{i}$ ve R'ye bağl1 olmasına karşın, TBDY2016'da; hi'ye, bina önem katsayısına (I), R'ye, dolgu duvar- çerçeve bağlantısının bitişik veya derzli olma durumuna, yapının doğal titreşim periyoduna $(T)$, aktif fay düzlemine uzaklığına, yerel zemin sınıfına $\left(Z_{\mathrm{A}}-\mathrm{Z}_{\mathrm{E}}\right)$ ve harita spektral ivme katsayılarına $\left(\mathrm{S}_{\mathrm{S}}, S_{1}\right)$ vb. birçok parametreye bağlı olarak belirlenmektedir.

TBDY2016'da etkin göreli kat ötelemeleri; sınırlandırılması dolgu duvarların çerçeveye bitişik imal edilmesi durumunda; 
$1 \lambda \frac{\delta_{i, \max }^{(X)}}{h_{i}} \leq 0,008$

dolgu duvar - çerçeve arasında esnek derzler kullanılması durumunda ise;

$\lambda \frac{\delta_{i, \max }^{(X)}}{h_{i}} \leq 0,016$

ifadelerine göre sınırlandırılmaktadır. $\mathrm{Bu}$ denklemlerde; $h_{i}$, kat yüksekliğini, $\delta_{i, \max }^{(\mathrm{X})}, \mathrm{x}$ doğrultusunda binanın i'inci katının etkin göreli kat ötelemelerinin kat içindeki en büyük değerini, $\lambda$ ise DD3 depremine (tekrarlanma periyodu 72 y1l) göre hesaplanan elastik tasarım spektral ivmesinin $\mathrm{S}_{\mathrm{ae}}(\mathrm{T})_{\mathrm{DD} 3}, \quad \mathrm{DD} 2$ depremine (tekrarlanma periyodu 475 yıl) göre hesaplanan elastik tasarım spektral ivmesine $\mathrm{S}_{\mathrm{ae}}(\mathrm{T})_{\mathrm{DD} 2}$ oran1,

$\lambda=\frac{S_{a e}(T)_{D D 3}}{S_{a e}(T)_{D D 2}}$

şeklinde ifade edilmektedir. Etkin göreli kat ötelemeleri; azaltılmış deprem yüklerine göre belirlenen göreli kat ötelemelerine $\left(\Delta_{\mathrm{i}}^{(\mathrm{X})}\right)$ bağlı olarak,

$\delta_{i, \max }^{(X)}=\frac{R}{I} \Delta_{i}^{(X)}$

ile elde edilmektedir. Bu çalışmanın hedefi olan yapıda izin verilen maksimum azaltılmış göreli kat ötelemeleri; yukarıdaki ifadenin 4 ve 5 denklemlerinde yerlerine konulması ile elde edilmektedir. Buna göre müsaade edinen maksimum azaltılmış göreli kat ötelemesi; dolgu duvar ile çerçevenin bitişik imal edilmesi durumunda (derzsiz),

$\Delta_{i}^{(X)} \leq \frac{0.008 \times h_{i} \times I}{R \times \lambda}$

dolgu duvar - çerçeve bağlantısının esnek derzlerle sağlanması durumunda (derzli),

$$
\Delta_{i}^{(X)} \leq \frac{0.016 \times h_{i} \times I}{R \times \lambda}
$$

olarak belirlenmektedir. TBDY2016 taslağındaki önemli yeniliklerden biri de; $\Delta_{\mathrm{i}}$ hesabında elastik tasarım spektral ivmelerinin, $\mathrm{S}_{\mathrm{ae}}(\mathrm{T})$ dahil olmasidir. Ayrıca, TBDY2016'da $\mathrm{S}_{\mathrm{ae}}(\mathrm{T})$ hesap yönteminde de önemli farklılıklar bulunmaktadır. $\Delta_{\mathrm{i}}$ hesabında, $\lambda$ katsayısı $\mathrm{S}_{\mathrm{ae}}(\mathrm{T})$ kullanılarak elde edileceğinden, bu çalışmada, $\mathrm{S}_{\mathrm{ae}}(\mathrm{T})$ hesabına da yer verilmiştir.

Elastik tasarım spekral ivmesinin hesaplanmasında öncelikle, yeni deprem tehlike haritalarından yapının inşa edileceği konuma dair kısa periyot için $S_{S}$ ve bir saniye periyot için $S_{1}$ harita spektral ivme katsayıları edinilmektedir. Daha sonra, haritadan elde edilen katsayılar kullanılarak,

$S_{D S}=S_{S} \times F_{S}$

$S_{D I}=S_{1} \times \gamma_{F} \times F_{1}$

eşitliklerinden tasarım spektral ivme katsayıları $S_{D S}$ ve $S_{D 1}$ elde edilmektedir. Burada, $F_{S}$ ve $\mathrm{F}_{1}$ yerel zemin etki katsayılarını, $\gamma_{\mathrm{F}}$ ise faya yakınlık katsayısını ifade etmektedir. $F_{S}$ ve $F_{1}$, yerel zemin sinıfi $\left(Z_{\mathrm{A}}-Z_{\mathrm{F}}\right), \mathrm{S}_{\mathrm{S}}$ ve $\mathrm{S}_{1}$ kullanılarak, sırasıyla Çizelge 1-2'den elde edilmektedir.

Çizelge 1. Kısa periyod bölgesi için Yerel Zemin Etki Katsayıları (TBDY2016 Tablo 2.1)

\begin{tabular}{|c|c|c|c|c|c|c|}
\hline \multirow{2}{*}{ Yerel Zemin Sınıfı } & \multicolumn{5}{|c|}{ Kısa periyot bölgesi için Yerel Zemin Etki Katsayısı $\mathrm{F}_{\mathrm{S}}$} \\
\cline { 2 - 7 } & $\mathrm{S}_{\mathrm{S}} \leq 0,25$ & $\mathrm{~S}_{\mathrm{S}}=0,50$ & $\mathrm{~S}_{\mathrm{S}}=0,75$ & $\mathrm{~S}_{\mathrm{S}}=1,00$ & $\mathrm{~S}_{\mathrm{S}}=1,25$ & $\mathrm{~S}_{\mathrm{S}} \geq 1,50$ \\
\hline $\mathrm{Z}_{\mathrm{A}}$ & 0,8 & 0,8 & 0,8 & 0,8 & 0,8 & 0,8 \\
\hline $\mathrm{Z}_{\mathrm{B}}$ & 0,9 & 0,9 & 0,9 & 0,9 & 0,9 & 0,9 \\
\hline $\mathrm{Z}_{\mathrm{C}}$ & 1,3 & 1,3 & 1,2 & 1,2 & 1,2 & 1,2 \\
\hline $\mathrm{Z}_{\mathrm{D}}$ & 1,6 & 1,4 & 1,2 & 1,1 & 1,0 & 1,0 \\
\hline $\mathrm{Z}_{\mathrm{E}}$ & 2,4 & 1,7 & 1,3 & 1,1 & 0,9 & 0,8 \\
\hline $\mathrm{Z}_{\mathrm{F}}$ & \multicolumn{7}{|c|}{ Sahaya özel zemin davranış analizi yapılacaktır } \\
\hline
\end{tabular}


Çizelge 2. 1.0 saniye periyod için Yerel Zemin Etki Katsayıları (TBDY2016 Tablo 2.2)

\begin{tabular}{|c|c|c|c|c|c|c|}
\hline \multirow{2}{*}{$\begin{array}{c}\text { Yerel Zemin } \\
\text { Sinıfi }\end{array}$} & \multicolumn{5}{|c|}{1.0 saniye periyot için Yerel Zemin Etki Katsayısı $\mathrm{F}_{1}$} \\
\cline { 2 - 7 } & $\mathrm{F}_{1} \leq 0,10$ & $\mathrm{~F}_{1}=0,20$ & $\mathrm{~F}_{1}=0,30$ & $\mathrm{~F}_{1}=0,40$ & $\mathrm{~F}_{1}=0,50$ & $\mathrm{~F}_{1} \geq 0,60$ \\
\hline $\mathrm{Z}_{\mathrm{A}}$ & 0,8 & 0,8 & 0,8 & 0,8 & 0,8 & 0,8 \\
\hline $\mathrm{Z}_{\mathrm{B}}$ & 0,8 & 0,8 & 0,8 & 0,8 & 0,8 & 0,8 \\
\hline $\mathrm{Z}_{\mathrm{C}}$ & 1,5 & 1,5 & 1,5 & 1,5 & 1,5 & 1,4 \\
\hline $\mathrm{Z}_{\mathrm{D}}$ & 2,4 & 2,2 & 2,0 & 1,9 & 1,8 & 1,7 \\
\hline $\mathrm{Z}_{\mathrm{E}}$ & 4,2 & 3,3 & 2,8 & 2,4 & 2,2 & 2,0 \\
\hline $\mathrm{Z}_{\mathrm{F}}$ & \multicolumn{7}{|c|}{ Sahaya özel zemin davranış analizi yapilacaktır } \\
\hline
\end{tabular}

$\gamma_{\mathrm{F}}$, DD-1 ve DD-2 deprem yer hareketi düzeyleri için aşağıda belirtilen durumlara göre hesaplanmakta; DD-3 ve DD-4 için ise "1" olarak kabul edilmektedir. $\mathrm{Bu}$ eşitliklerdeki $\mathrm{L}_{\mathrm{F}}$, fay düzlemine olan mesafeyi ifade etmektedir.

$\gamma_{F}=1,2, \quad L_{F} \leq 15 \mathrm{~km}$

$\gamma_{F}=1,2-0,02\left(L_{F}-15\right)\left\{\begin{array}{l}15 \mathrm{~km} \leq L_{F} \\ L_{F} \leq 25 \mathrm{~km}\end{array}\right.$

Tasarım köșe periyotları $T_{A}$ ve $T_{B}$, doğal titreşim periyodu $T$ ve yerdeğiştirme bölgesine geçiş periyodu $\mathrm{T}_{\mathrm{L}}(6 \mathrm{sn})$ olmak üzere yapının elastik tasarım spektral ivme değerleri $\mathrm{S}_{\mathrm{ae}}(\mathrm{T})$,

$S_{a e}(T)=\left(0,4+0,6 \frac{T}{T_{A}}\right) \times S_{D S} \quad\left(0 \leq T \leq T_{A}\right)$

$S_{a e}(T)=S_{D S} \quad\left(T_{A} \leq T \leq T_{B}\right)$

$S_{a e}(T)=\frac{S_{D 1}}{T} \quad\left(T_{B} \leq T \leq T_{L}\right)$

$S_{a e}(T)=\frac{S_{D 1} \times T_{L}}{T^{2}} \quad\left(T_{L} \leq T\right)$ şeklinde belirtilen aralıklara göre hesaplamaktadır. Bu ifade DD-2 ve DD-3 deprem düzeyleri için ayrı ayrı hesaplanarak alt1 numaralı denklem hesaplanmaktadır

\section{3. İLLERE GÖRE MAKSIMUM AZALTILMISS GÖRELI KAT ÖTELEME DEĞERLERİ}

Bu çalışmada, TBDY2016 ve DBYBHY2007'de "etkin göreli kat ötelemelerinin sinırlandırılması" bölümündeki kurala göre bütün iller için izin verilen en büyük göreli kat ötelemeleri hesaplanmıştır. Çalışmanın kapsamı, bina önem katsayısı 1 olan ve taşıyıcı sistem davranış katsayısı 8 olan yap1 stoğumuzun büyük bir çoğunluğunu kapsayan taşıyıcı sistemler ile sınırlandırılmıştır. $\mathrm{Bu}$ çalışmada hesaplarda dikkate alınan il merkezlerinin enlem ve boylamları Çizelge 3 'te sunulmuştur.

Çizelge 3. Hesaplamaların yapıldığı il merkezlerinin enlem ve boylamları

\begin{tabular}{|c|c|c|c|c|c|c|c|c|}
\hline İ & Enlem & Boylam & il & Enlem & Boylam & ì & Enlem & Boylam \\
\hline Adana & 37,1075 & 35,3825 & Giresun & 40,9177 & 38,3844 & Samsun & 41,2908 & 36,3361 \\
\hline Adıyaman & 37,7628 & 38,2756 & Gümüşhane & 40,4594 & 39,4803 & Siirt & 37,9274 & 41,9422 \\
\hline Afyon & 38,7573 & 30,5382 & Hakkari & 37,5774 & 43,7366 & Sinop & 42,0266 & 35,1512 \\
\hline Ağr1 & 39,7193 & 43,0509 & Hatay & 36,2026 & 36,1602 & Sivas & 39,7505 & 37,015 \\
\hline Amasya & 40,6562 & 35,8373 & Isparta & 37,767 & 30,5535 & Tekirdağ & 40,9786 & 27,5152 \\
\hline Ankara & 39,9208 & 32,854 & İçel & 36,781 & 34,5877 & Tokat & 40,314 & 36,5513 \\
\hline
\end{tabular}


Çizelge 3. Hesaplamaların yapıldığı il merkezlerinin enlem ve boylamları (Devamı)

\begin{tabular}{|c|c|c|c|c|c|c|c|c|}
\hline İl & Enlem & Boylam & İl & Enlem & Boylam & İl & Enlem & Boylam \\
\hline Antalya & 36,8869 & 30,7062 & İstanbul & 40,9878 & 29,0368 & Trabzon & 41,0064 & 39,7109 \\
\hline Artvin & 41,1812 & 41,8205 & İzmir & 38,419 & 27,1277 & Tunceli & 39,0758 & 39,5337 \\
\hline Aydın & 37,8471 & 27,8437 & Kars & 40,601 & 43,0944 & Şanlıurfa & 37,1601 & 38,7989 \\
\hline Balıkesir & 39,6474 & 27,8864 & Kastamonu & 41,3777 & 33,7763 & Uşak & 38,6742 & 29,4057 \\
\hline Bilecik & 40,1426 & 29,9793 & Kayseri & 38,7227 & 35,4869 & Van & 38,5038 & 43,3955 \\
\hline Bingöl & 38,8832 & 40,4929 & Kırklareli & 41,7341 & 27,2191 & Yozgat & 39,8221 & 34,8081 \\
\hline Bitlis & 38,4053 & 42,1079 & Kırşehir & 39,1462 & 34,1606 & Zonguldak & 41,4549 & 31,7886 \\
\hline Bolu & 40,7327 & 31,6087 & Kocaeli & 40,7651 & 29,9445 & Aksaray & 38,3703 & 34,0272 \\
\hline Burdur & 37,7183 & 30,2822 & Konya & 37,8718 & 32,5005 & Bayburt & 40,2593 & 40,2268 \\
\hline Bursa & 40,1972 & 29,0615 & Kütahya & 39,4192 & 29,9853 & Karaman & 37,1701 & 33,223 \\
\hline Çanakkale & 40,15 & 26,4027 & Malatya & 38,3487 & 38,3189 & Kirıkkale & 39,8437 & 33,5056 \\
\hline Çankırı & 40,6002 & 33,6164 & Manisa & 38,6139 & 27,4337 & Batman & 37,8999 & 41,1311 \\
\hline Çorum & 40,55 & 34,9539 & $\mathrm{~K}$, Maraş & 37,5775 & 36,9266 & Şırnak & 37,5212 & 42,4556 \\
\hline Denizli & 37,7829 & 29,0963 & Mardin & 37,321 & 40,725 & Bartın & 41,6265 & 32,3299 \\
\hline Diyarbakır & 37,9367 & 40,2075 & Muğla & 37,2152 & 28,3639 & Ardahan & 41,113 & 42,7022 \\
\hline Edirne & 41,6769 & 26,5529 & Muş & 38,7449 & 41,4998 & Iğdır & 39,9233 & 44,0457 \\
\hline 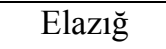 & 38,6749 & 39,2208 & Nevşehir & 38,627 & 34,7207 & Yalova & 40,6585 & 29,2743 \\
\hline Erzincan & 39,7468 & 39,491 & Niğde & 37,9703 & 34,6769 & Karabük & 41,1956 & 32,6231 \\
\hline Erzurum & 39,9056 & 41,2684 & Ordu & 40,9845 & 37,8758 & Kilis & 36,7155 & 37,1141 \\
\hline Eskişehir & 39,7658 & 30,5238 & Rize & 41,0271 & 40,5177 & Osmaniye & 37,0747 & 36,2465 \\
\hline Gaziantep & 37,063 & 37,3792 & Sakarya & 40,8511 & 30,3164 & Düzce & 40,8403 & 31,1546 \\
\hline
\end{tabular}

Yapılan hesaplamalarda kat yüksekliği 3 m olarak sabit tutulmuştur. Zemin türünün, azaltılmış göreli kat öteleme sınırına etkisinin daha iyi anlaşılması için TBDY2016'da tanımlanan güçlü $\left(Z_{\mathrm{A}}\right)$ ve zayıf $\left(\mathrm{Z}_{\mathrm{E}}\right)$ zemin türleri arasında kıyaslama yapılmıştır. Doğal titreşim periyodu ve yapının konumuna bağlı olarak harita spektral ivme katsayıları değişken parametrelerdir. Doğal titreşim periyodu, 0,2'den başlayarak 0,1 aralıklarla arttırılarak her bir il için maksimum azaltılmış göreli kat ötelemeleri ayrı ayrı hesaplanmıştır. Değişken parametreleri tanımlayan kısaltmalar Çizelge 4'te gösterilmiștir. Çizelge 4'te belirtilen her bir durum için analizler yinelenmiştir.

TBDY2016'ya göre hesaplanan maksimum azaltılmış göreli kat ötelemeleri; dolgu duvar çerçeve bağlantısının derzli olduğu durumlar için Şekil 1'de, bitişik olduğu durumlar için ise Şekil 2'de doğal titreşim periyodu ve zemin türüne bağlı olarak her bir il merkezi için ayrı ayrı gösterilmiştir. Benzer şekilde DBYBHY2007'ye göre aynı durumlar için elde edilen sonuçlar da aynı şekiller üzerinde gösterilmiştir. Şekil 1 ve 
Şekil 2'de farklı durumlar için elde edilen ötelemelerin en büyüğü Şekil 3’te, DBYBHY2007 öteleme sınırları ile birlikte sunulmuştur.

Çizelge 4. Parametreler ve kısaltmaları

\begin{tabular}{|c|c|c|c|}
\hline Kisaltma & $\begin{array}{l}\text { Bağlantı } \\
\text { Durumu }\end{array}$ & $\begin{array}{c}\text { Zemin } \\
\text { Türü }\end{array}$ & Periyot \\
\hline $\mathrm{D} 2 \mathrm{~A}$ & Derzli & $\mathrm{Z}_{\mathrm{A}}$ & 0,2 \\
\hline D3A & Derzli & $\mathrm{Z}_{\mathrm{A}}$ & 0,3 \\
\hline D4A & Derzli & $\mathrm{Z}_{\mathrm{A}}$ & 0,4 \\
\hline D5A & Derzli & $\mathrm{Z}_{\mathrm{A}}$ & $\mathrm{T} \geq 0,5$ \\
\hline $\mathrm{D} 4 \mathrm{E}$ & Derzli & $\mathrm{Z}_{\mathrm{E}}$ & $0,2 \geq \mathrm{T} \geq 0,4$ \\
\hline D5E & Derzli & $\mathrm{Z}_{\mathrm{E}}$ & $\mathrm{T}=0,5$ \\
\hline D6E & Derzli & $\mathrm{Z}_{\mathrm{E}}$ & $\mathrm{T}=0,6$ \\
\hline D7E & Derzli & $\mathrm{Z}_{\mathrm{E}}$ & $\mathrm{T}=0,7$ \\
\hline D8E & Derzli & $\mathrm{Z}_{\mathrm{E}}$ & $\mathrm{T}=0,8$ \\
\hline D9E & Derzli & $\mathrm{Z}_{\mathrm{E}}$ & $\mathrm{T}=0,9$ \\
\hline D10E & Derzli & $\mathrm{Z}_{\mathrm{E}}$ & $\mathrm{T} \geq 1,0$ \\
\hline Dmax & \multicolumn{3}{|c|}{$\begin{array}{l}\text { Derzli bağlantı durumlarından elde } \\
\text { edilen azaltılmış göreli kat } \\
\text { ötelemelerinin en büyüğ̈ü }\end{array}$} \\
\hline B2A & Bitişik & $\mathrm{Z}_{\mathrm{A}}$ & $\mathrm{T}=0,2$ \\
\hline B3A & Bitişik & $\mathrm{Z}_{\mathrm{A}}$ & $\mathrm{T}=0,3$ \\
\hline B4A & Bitişik & $\mathrm{Z}_{\mathrm{A}}$ & $\mathrm{T}=0,4$ \\
\hline B5A & Bitişik & $\mathrm{Z}_{\mathrm{A}}$ & $\mathrm{T} \geq 0,5$ \\
\hline B4E & Bitişik & $\mathrm{Z}_{\mathrm{E}}$ & $0,2 \geq \mathrm{T} \geq 0,4$ \\
\hline B5E & Bitişik & $\mathrm{Z}_{\mathrm{E}}$ & $\mathrm{T}=0,5$ \\
\hline B6E & Bitişik & $\mathrm{Z}_{\mathrm{E}}$ & $\mathrm{T}=0,6$ \\
\hline B7E & Bitişik & $\mathrm{Z}_{\mathrm{E}}$ & $\mathrm{T}=0,7$ \\
\hline B8E & Bitişik & $\mathrm{Z}_{\mathrm{E}}$ & $\mathrm{T}=0,8$ \\
\hline B9E & Bitişik & $\mathrm{Z}_{\mathrm{E}}$ & $\mathrm{T}=0,9$ \\
\hline B $10 \mathrm{E}$ & Bitişik & $Z_{E}$ & $\mathrm{~T} \geq 1,0$ \\
\hline$B \max$ & \multicolumn{3}{|c|}{$\begin{array}{l}\text { Bitişik bağlantı durumlarından elde } \\
\text { edilen azaltılmış göreli kat } \\
\text { ötelemelerinin en büyüğü }\end{array}$} \\
\hline $\begin{array}{l}\text { DBYBHY } \\
2007\end{array}$ & \multicolumn{3}{|c|}{$\begin{array}{l}\text { DBYBHY2007'ye göre elde edilen } \\
\text { maksimum azaltılmış göreli kat } \\
\text { ötelemeleri }\end{array}$} \\
\hline
\end{tabular}

\section{BULGULAR}

Şekil 1 ve Şekil 2 incelendiğinde Kırşehir, Konya, Mardin, Nevşehir ve Şanlıurfa dışındaki bütün illerde $\mathrm{Z}_{\mathrm{A}}$ türü zemine inşa edilecek betonarme binalarda $Z_{\mathrm{E}}$ zemin türüne göre daha yüksek azaltılmış göreli kat ötelemelerine müsaade edildiği görülmektedir.

Yüksek öteleme değerleri, bazı bölgelerde yüksek periyotlara sahip binalarda elde edilirken, bazı bölgelerde düşük periyotlara sahip binalarda elde edilmektedir. Bundan dolayı, periyot ile maksimum azaltılmış göreli kat ötelemeleri arasında doğrusal bir ilişki kurulamamaktadır.

Azaltılmış göreli kat ötelemesi sınırının derzli ve bitişik dolgu duvar - çerçeve bağlantıları için, $\mathrm{Z}_{\mathrm{A}}$ zemin türüne göre $0,2-0,5$ periyot aralığında farklılık gösterdiği, 0,5 'ten büyük periyot değerlerinde değişmediği görülmüsstür. $Z_{\mathrm{E}}$ zemin türüne göre hesaplanan azaltılmış göreli kat öteleme sinırında, $0,2-0,4$ ve 1,0 'den büyük periyot değerleri için bir değişiklik olmadığı, $0,4-1,0$ periyot aralığında değiştiği görülmüştür (Şekil 1 ve 2).

DBYBHY2007'ye göre göreli kat ötelemesi sınır değeri; $h_{i}$ ve R'ye bağlı olduğundan, bu iki değeri aynı olan yapıların tümü, bulundukları bölgenin depremselliğinden bağımsız olarak, aynı olmaktadır (Şekil 1 ve 2). Bu çalışmada değerlendirilen yapıların tümü için bu değer 7,5 mm olarak hesaplanmıştır.

Dolgu duvar ile çerçevenin bitişik imal edildiği yapılar için bulunan azaltılmış göreli kat ötelemesi sınırı, derzli imal edilen yapıların öteleme sınırının yarısı kadar olduğu 8 ve 9 numaralı denklemlerden anlaşılmaktadır.

\section{SONUÇLAR}

Bu çalışmada, Türkiye'deki her bir il merkezinden seçilen noktalar üzerinde inşa edilecek taşıyıcı sistem davranış katsayısı 8 , bina önem katsayısı 1 , kat yüksekliği $3 \mathrm{~m}$ ve zemin türü $Z_{\mathrm{A}}$ veya $Z_{\mathrm{E}}$ olan 
Maksimum Azaltılmış Göreli Kat Ötelemesi (mm)

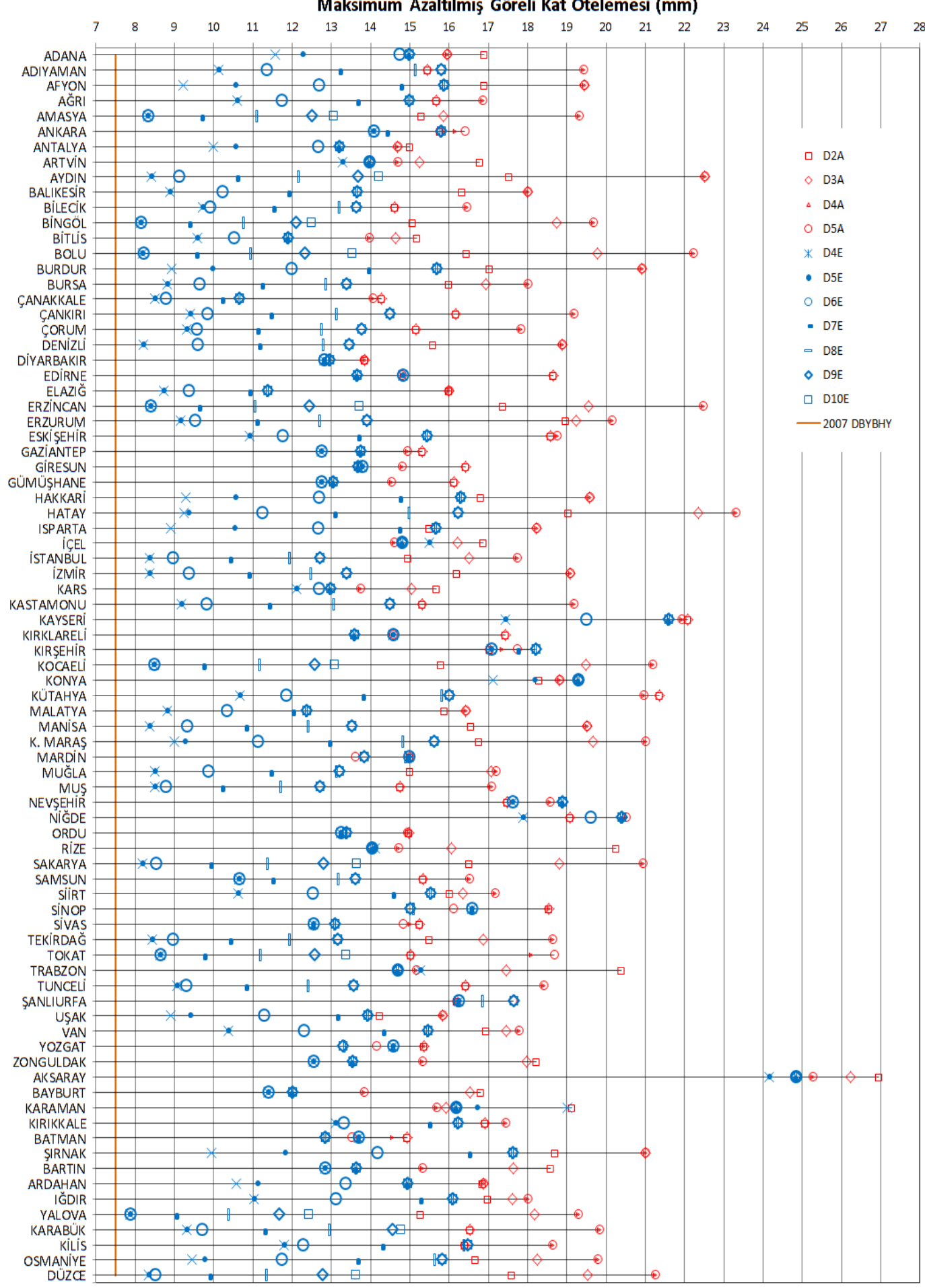

Şekil 1. Derzli çerçeve-dolgu duvar bağlantısı için maksimum azaltılmış göreli kat ötelemeleri 
Maksimum Azaltılmış Göreli Kat Ötelemelerinin Güncel (DBYBHY2007) ve Yeni Yönetmelik Taslağına (TBDY2016) Göre Mukayesesi

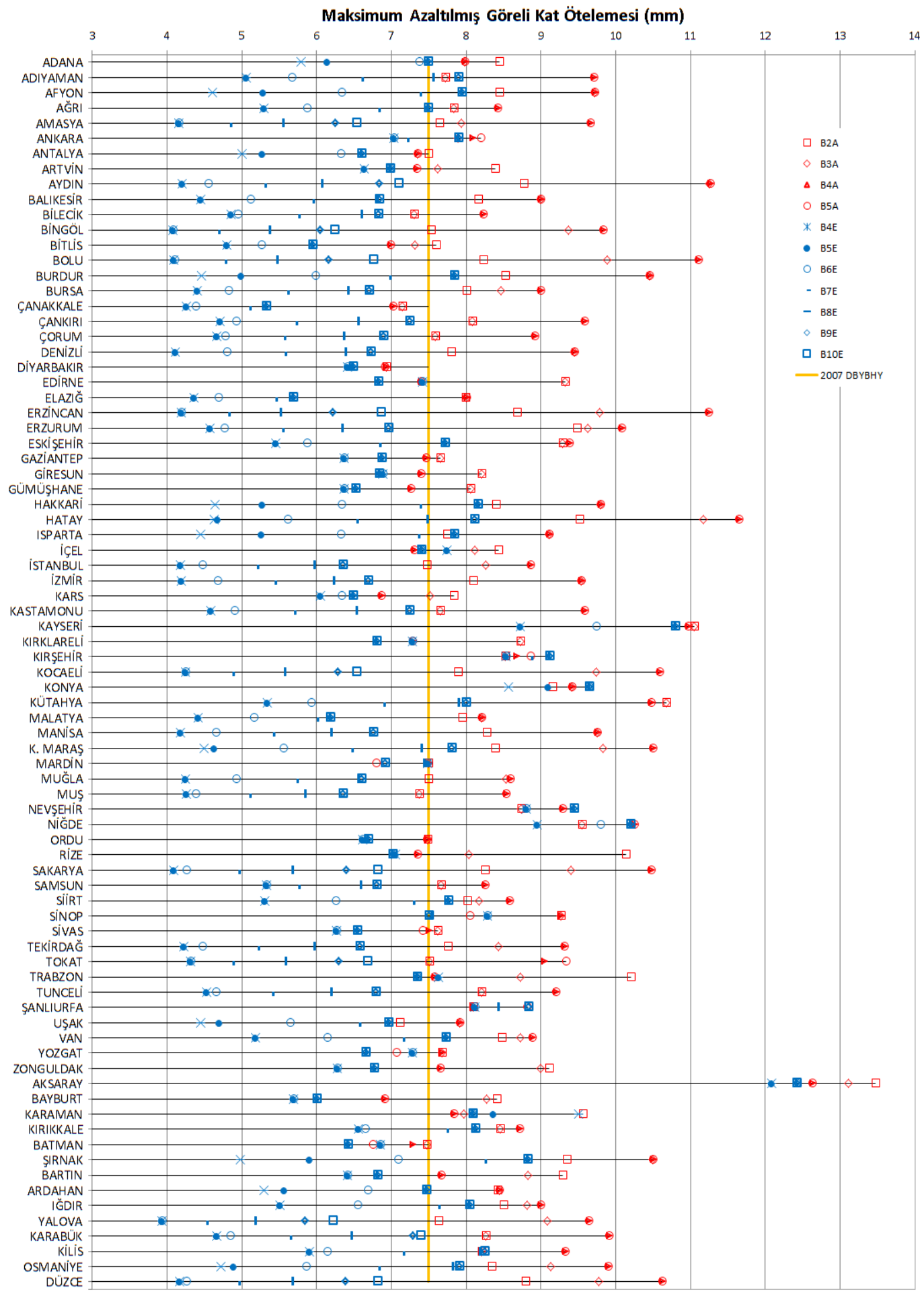

Şekil 2. Bitişik çerçeve-dolgu duvar bağlantısı (derzsiz) için maksimum azaltılmış göreli kat ötelemeleri 


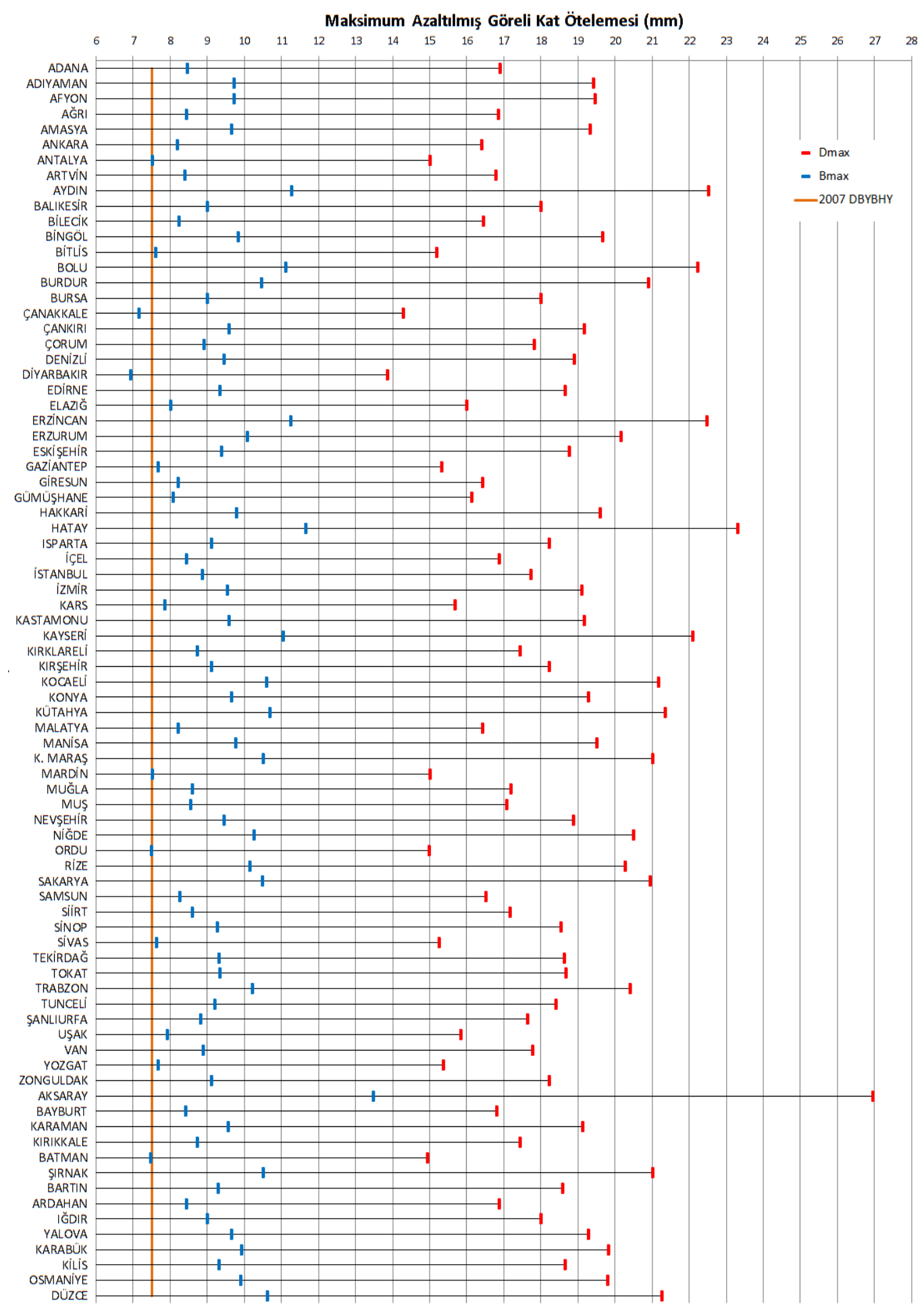

Şekil 3. Her bir il için elde edilen en büyük azaltılmış göreli kat ötelemeleri 
binaların farklı doğal titreşim periyotları için TBDY2016 ve DBYBHY2007'ye göre izin verilen en büyük azaltılmış göreli kat ötelemeleri elde edilmiştir. Hesaplanan değerlerden aşağıdaki sonuçlara ulaşılmaktadır;

- İllerin büyük çoğunluğunda azaltılmış göreli kat ötelemelerinin sinırları $Z_{\mathrm{E}}$ yerel zemin sınıfına kıyasla $Z_{\mathrm{A}}$ yerel zemin sınıfı için daha yüksek olduğu görülmektedir. Ancak, tersi durumların da mevcut olduğu için genelleme yapmak mümkün değildir

- Dolgu duvar - çerçeve bağlantısının derzli olduğu yapılarda bitişik olan yapılara göre 2 kat daha fazla ötelemeye müsaade edilmektedir.

- Azaltılmış göreli kat ötelemesi sınırlar değeri hesabında, DBYBHY2007'de dolgu duvar çerçeve bağlantısının derzli olma durumu mevcut olmadığından, sadece bitişik olma durumu için 2017 TBDY ile kıyaslama yapılabilmektedir. Buna göre; bir önceki yönetmeliğe göre TBDY2016'da illerin büyük çoğunluğunda daha büyük ötelemelere müsaade edilmektedir.

- TBDY2016’ya göre azaltılmış göreli kat öteleme sınırı, belirli bir eğilimde olmayan parametrelere bağlı olduğundan, yapının inşa edileceği her nokta için ayrı ayrı hesaplanmalıdır.

- Elde edilen öteleme sınırları, derzli dolgu duvar - çerçeve bağlantı elemanlarının derz büyüklüklerinin belirlenmesine yardımcı olacaktır.

\section{KAYNAKLAR}

1. Zhou, J., Bu, G.B., Li., K.N., 2012. Calculation Methods for Inter-Story Drifts of Building Structures, $15^{\text {th }}$ World Conf. Earthq. Eng., no. 3, p. 7 .

2. Sindel, Z., Akbaş, R., Tezcan., S.S., 1996. Drift Control and Damage in Tall Buildings, Eng. Struct., vol. 18, no. 12, pp. 957-966.

3. TBDY, 2016. Türkiye Bina Deprem
Yönetmeliği, AFAD.

4. DBYBHY, 2007. Deprem Bölgelerinde Yapılacak Binalar Hakkında Yönetmelik. Bayındırılık ve İskan Bakanlığı. 